\title{
Financiarización, valorización inmobiliaria del capital y mercantilización de la metamorfosis urbana
}

GARLOS A. DE MATTOS*

\section{Resumen}

Durante las últimas décadas del siglo pasado, como consecuencia de la imposición de una nueva configuración capitalista estructurada en base al predominio de lo financiero sobre lo productivo, se produjo una ruptura en la dinámica económica dominante que cambió radicalmente el encuadramiento de los procesos sociales que allí se desarrollaban. Bajo el impacto de la financiarización, se desencadenó una metamorfosis, en cuyo transcurso, asociadas a un explosivo aumento de la conectividad y la movilidad, se modificaron las relaciones entre las principales áreas urbanas del mundo, que así pasaron a constituirse en componentes de una Red Urbana Global. Y, al mismo tiempo, en la medida que cada una de esas áreas se articuló a dicha Red, se produjeron sustantivas mutaciones que afectaron su organización, funcionamiento, morfología y paisaje. En virtud de estas mutaciones, la entidad que había sido identificada bajo la denominación de "ciudad", ha tendido a irse diluyendo en ilimitados espacios urbanos, cuya presencia se puede observar en distintas partes del mundo. ${ }^{1}$

Palabras clave: Financiarización. Mercantilización. Metamorfosis urbana. Red urbana global

\footnotetext{
* Pontificia Universidad Católica (Chile)

${ }^{1}$ Artículo preparado como parte de los trabajos desarrollados para el Proyecto FONDECYT $N^{\circ}$ 1.141.147, "Nueva geografía de la urbanización y vulnerabilidad socio-territorial, ìhacia la configuración de una región urbana en Santiago de Chile".
} 


\section{Financialization, real estate capital appreciation and commodification of urban metamorphosis}

\section{Abstract}

Throughout the late decades of the last century, because of the imposition of a new capitalist structure based on the predominance of financial markets over the productive ones, there was a rupture in the dominant economic dynamics, which has radically changed the framework within which the social processes developed. The financialization of the economy has triggered a metamorphosis, during which process, associated with an explosive increase in connectivity and mobility, there was a change in the relations between the major urban areas of the world, which became components of a Global Urban Network. At the same time, insofar as each of these areas has articulated to such Network, substantive mutations have occurred that affected the organization, functioning, morphology and landscape of these areas. Due to these mutations, the entity that had once been designated as "city" tended to have its boundaries blurred across unlimited urban spaces, whose presence can be seen in different parts of the world.

Keywords: Financialization. Commodification. Urban metamorphosis. Global urban network.

En tanto que ligada a las fuerzas productivas y fuerza productiva ella misma, la ciudad es la sede de lo económico y de su monstruoso poder. En ella, en el curso de la historia (la suya), el valor de cambio ha vencido lentamente al valor de uso; esta lucha se escribió sobre las murallas de las ciudades, sobre los edificios, en las calles las ciudades llevan y testimonian su huella (Lefebvre, 1972b, p. 103). 


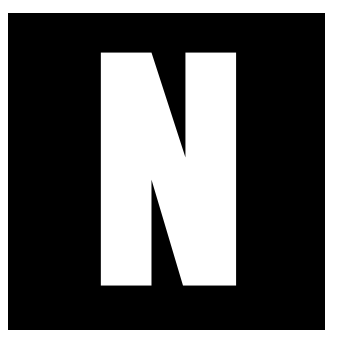

umerosos estudios sobre las transformaciones urbanas que se produjeron prácticamente en el mundo entero durante las últimas décadas, apuntan a que las mismas constituyen un componente inherente a los cambios que caracterizan al desarrollo capitalista a partir de la crisis del régimen de acumulación keynesiano-fordista. Y, en general, aceptan que las mismas forman parte de la evolución hacia la urbanización generalizada de la economía y la sociedad, la cual comenzó a procesarse bajo los efectos de los cambios en el comportamiento locacional de las principales actividades productivas ocasionadas por la revolución industrial.

Se entiende que, en este contexto, comenzó a procesarse una metamorfosis que habría de provocar una desestructuración y restructuración de la entidad hasta entonces identificada como "ciudad", la cual ha tendido a diluirse en espacios urbanos que se expanden en forma ilimitada en distintas partes del mundo (Lefebvre, 1989; Brenner, 2013). Y que, en lo esencial, esto responde a que, como señaló Lefebvre (1970),

la concentración de la población se realiza al mismo tiempo que la de los medios de producción. El tejido urbano prolifera, se extiende, consumiendo los residuos de vida agraria. Por tejido urbano no se entiende, de manera estrecha, la parte construida de las ciudades, sino el conjunto de manifestaciones del predominio de la ciudad sobre el campo (pag. 9-10).

Fue así, que dicho proceso de proliferación y extensión del tejido urbano, por el que comenzaron a ser consumidos los residuos remanentes de vida agraria, tuvo su expresión germinal y más potente en los lugares donde la revolución industrial presentó sus primeras manifestaciones. Lugares desde los cuales tendió, posteriormente, a difundirse hacia otras partes del planeta, para lograr luego su apogeo bajo los efectos de la restructuración neoliberal, la revolución informacional y la globalización financiera. 
En este sentido, el análisis de las raíces estructurales de esta metamorfosis urbana respalda la conclusión de que, en lo fundamental, ellas se fueron generando y profundizando, asociadas a los cambios que afectaron a las relaciones sociales de producción a todo lo largo del proceso de desarrollo del capitalismo. Frente a este proceso, resulta fundamental entender que las transformaciones urbanas no son un mero resultado del crecimiento económico, sino que, como fue destacado por Lefebvre,

La ciudad se transforma no sólo en razón de 'procesos globales' relativamente continuos (tales como el crecimiento de la producción material en el curso de las épocas con sus consecuencias en los intercambios, o el desarrollo de la racionalidad) sino en función de modificaciones profundas en el modo de producción, en las relaciones 'ciudad-campo', en las relaciones de clase y de propiedad (Lefebvre, 1968, p. 59)

\section{Producción social del espacio urbano y supervivencia del capitalismo}

La aceptación de este enfoque, lleva a considerar que el marco teórico que permite una mejor explicación sobre la generación y evolución de estos procesos se sustenta fundamentalmente en las ideas planteadas y desarrolladas por Lefebvre, en cuanto a que "el espacio (social) es un producto (social)", que resulta del hecho de que cada sociedad (esto es, cada modo de producción, con las diversidades que engloba) produce su espacio y, en particular, su espacio urbano. Este se desarrolla en procesos en los que la naturaleza "no es más que la materia prima sobre la que operan las fuerzas productivas de sociedades diversas para producir su espacio" (Lefebvre, 1974, p. 39-40). Y donde ese continuado proceso de producción social de espacio cumple un papel fundamental para permitir la reproducción y la supervivencia del capitalismo: "el capitalismo ha 
podido atenuar [...] sus contradicciones internas y en consecuencia ha logrado el 'crecimiento' [...]. ¿Por qué medios? [...] ocupando el espacio, produciendo un espacio" (Lefebvre, 1972a, p. 15).

Si continuamos el análisis desde la perspectiva lefebvriana de la producción social del espacio, deberemos llegar a la conclusión de que lo que ahora identificamos bajo la denominación de globalización, alude a un fenómeno que siempre ha estado presente en la historia del capitalismo, aun cuando con el proceso respectivo haya logrado diferentes dimensiones geográficas en cada una de sus fases. En esta dirección, tanto Wallerstein (1974) como Braudel (1985) han sostenido que el capitalismo se desarrolló desde sus orígenes en tanto "sistema" o "economía mundo", el cual, desde entonces, pasó a ubicarse como un rasgo constitutivo de este tipo de formación social, pues:

el capitalismo es una creación de la desigualdad del mundo: necesita, para desarrollarse, la complicidad de la economía internacional. Es hijo de la organización autoritaria de un espacio evidentemente desmesurado. No hubiera crecido con semejante fuerza en un espacio económico limitado. $Y$ quizás no hubiese crecido en absoluto de no haber recurrido al trabajo ancilar de otros (Braudel, 1985, pag. 106).

Eso supone que, en el curso de su larga y conflictiva historia, el proceso de producción social del espacio en el capitalismo estuvo marcado por su progresiva expansión geográfica y su articulación sistémica en tanto "economía-mundo", hasta llegar a lo que hoy denominamos como economía global. En este proceso, a medida que las relaciones capitalistas de producción fueron logrando imponerse en nuevos lugares de un ámbito territorial cada día más amplio, se fue produciendo una intensificación de la articulación entre los lugares originarios y los que fueron siendo incorporados a esa economía-mundo que, en cada una de sus fases, se fue haciendo geográficamente más extensa. De esta forma, ésta se fue 
expandiendo hasta conformarse en un espacio mundial de acumulación, que representa la culminación de dicho proceso. En este sentido, la globalización se puede considerar como el lógico y previsible desenlace de un proceso de producción social de espacio, cuya continuidad ha permitido hasta ahora la reproducción y supervivencia de la sociedad capitalista.

Cuando se intenta establecer las razones que produjeron la intensificación de las articulaciones entre los principales componentes de la economía capitalista a escala global, debemos tener presente que los arreglos institucionales que viabilizaron la dinámica respectiva fueron concebidos e impulsados por el Estado y "la clase que ostenta la hegemonía", bajo la convicción de que "todo es válido para legitimar, para entronizar, un orden general, que corresponde a la lógica de la mercancía, a su "mundo", realizado a escala verdaderamente mundial por el capitalismo y por la burguesía" (Lefebvre 1970, pag. 49). Bajo esta motivación fue que se ubicó al crecimiento económico como el objetivo básico de la gestión estatal, y se generó un proceso que alcanzó su apogeo cuando, durante las últimas décadas del siglo pasado, un número creciente de países se adscribió a los principios y criterios del discurso neoliberal.

A lo largo de ese proceso, en el que se fue entronizando ese orden general regido por la lógica de la mercancía, los gobiernos de los principales países involucrados en el mismo, fueron realizando diversos y variados arreglos institucionales, considerados como requisito para la afirmación de las relaciones sociales capitalistas en una economía-mundo en expansión. En esa trayectoria, la dinámica que se fue desplegando y profundizando, impulsada por los intereses y las demandas de las fuerzas sociales que buscaron imponer el orden general regido por la lógica de la mercancía, evolucionó desde una situación marcada por el despliegue de la industrialización y por la generalización del consumo, hacia otra en la que el sector productivo perdió fuerza ante la imposición de la lógica fi- 
nanciera. En ese proceso, que debió enfrentar múltiples contradicciones, crisis y mutaciones, se transitó por tres configuraciones sucesivas: inter-nacional, multi-nacional y financiera (Michalet, 2004 y 2007), en las que los cambios estructurales constitutivos de cada una de esas fases fueron dejando su huella en la metamorfosis urbana (ver Tabla 1).

Tabla 1. Evolución configuraciones capitalistas en la época de la globalización

\begin{tabular}{|c|c|c|}
\hline $\begin{array}{l}\text { CONFIGURACIÓN } \\
\text { INTERNACIONAL }\end{array}$ & $\begin{array}{l}\text { CONFIGURACIÓN } \\
\text { MULTINACIONAL }\end{array}$ & $\begin{array}{l}\text { CONFIGURACIÓN } \\
\text { FINANCIERA }\end{array}$ \\
\hline $\begin{array}{l}\text { Actor dominante: } \\
\text { Estados Nacionales }\end{array}$ & $\begin{array}{c}\text { Actor dominante: } \\
\text { empresas multinacionales }\end{array}$ & $\begin{array}{l}\text { Actor dominante: } \\
\text { instituciones financieras }\end{array}$ \\
\hline $\begin{array}{c}\text { Desde la crisis del } 29 \text { hasta } \\
\text { fines de los } 60\end{array}$ & $\begin{array}{l}\text { Desde la crisis de los } 60 \\
\text { hasta mediados de los } 80\end{array}$ & $\begin{array}{l}\text { Desde fines de los } 70 \text { en } \\
\text { delante }\end{array}$ \\
\hline \multirow{2}{*}{$\begin{array}{l}\text { Es básicamente en torno } \\
\text { a las decisiones de los } \\
\text { Estado-nación que se } \\
\text { estructura un proceso de } \\
\text { inter-nacionalización, en } \\
\text { base al predominio de los } \\
\text { intercambios comerciales } \\
\text { de bienes }\end{array}$} & $\begin{array}{l}\text { Las inversiones directas en } \\
\text { el extranjero (IDE) ocupan } \\
\text { un lugar dominante y } \\
\text { aumenta la importancia } \\
\text { mundial del comercio inter- } \\
\text {-empresas }\end{array}$ & $\begin{array}{l}\text { Se impone la lógica finan- } \\
\text { ciera, que se desborda } \\
\text { hacia las dimensiones } \\
\text { "reales" de la economía; las } \\
\text { diferentes plazas financieras } \\
\text { se articulan en base a redes } \\
\text { mundiales }\end{array}$ \\
\hline & \multicolumn{2}{|c|}{$\begin{array}{c}\text { La competitividad se impone como criterio básico de } \\
\text { la lógica económica, donde predomina la concurrencia } \\
\text { oligopólica y la multi-nacionalización se impone en las } \\
\text { estrategias empresariales }\end{array}$} \\
\hline
\end{tabular}

Fuente: Michalet, 2003 


\section{Configuración financiera, nuevo encuadramiento estructural}

El intento de análisis y explicación sobre la dirección y el alcance de dicha metamorfosis urbana reposa en la convicción de que, para que el mismo resulte consistente y convincente, es imprescindible hacerlo a la luz de los cambios en las relaciones de producción que se produjeron con el tránsito desde la configuración transnacional hasta la configuración financiera. Desde este punto de vista, se puede comprobar que esta configuración financiera dominante a escala planetaria consolidó una dinámica económica regida por la lógica mercantil, que es lo que permite explicar lo esencial de las mutaciones estructurales que actualmente se están procesando.

¿Cómo influyeron estas mutaciones sobre la actual metamorfosis urbana? Al respecto, debemos considerar que en el desencadenamiento de esta metamorfosis ante todo tuvieron una decisiva incidencia las mutaciones estructurales que caracterizan a la fase posfordista, en la que se fueron imponiendo las configuraciones caracterizadas por Michalet. Estas configuraciones, que evolucionaron bajo los efectos de un explosivo crecimiento de la población mundial, de la continua urbanización de la economía y de los impactos en términos de conectividad y movilidad de las tecnologías de la información y las comunicaciones (TIC), culmina con la actual "configuración financiera" (Michalet, 2007, p. 77), o régimen de acumulación financiarizado (Chesnais, 2010), que tiende a imponerse a escala planetaria.

De hecho, fue desde las últimas décadas del siglo pasado cuando, frente a los síntomas de agotamiento y crisis del régimen de acumulación keynesiano-fordista, que diversos gobiernos comenzaron a adscribirse al discurso que preconizaba la necesidad de un "ajuste estructural" que permitiese reafirmar el orden general regido por la lógica del mercado, que se consideraba que había sido debilitado como consecuencia de las reformas 
y políticas de fundamento keynesiano. Al estimar que este cambio de enfoque era imprescindible para recuperar la dinámica de acumulación y crecimiento, esos gobiernos procedieron a aplicar, bajo distintas modalidades, un conjunto de reformas y políticas de liberalización económica que redundaron en un radical cambio de rumbo con respecto al período anterior.

De tal forma, las sucesivas reformas impulsadas por los Estados-nación que se fueron articulando en la "economía-mundo" capitalista, lograron materializar la transición de una dinámica económica estructurada en torno al sector industrial hacia otra en que ese papel que pasó a ser cumplido por el sector financiero. Como resultado de este cambio que llevó a la consolidación de un régimen de acumulación conducido por las finanzas, bajo cuya vigencia se produjo la revitalización de la mercantilización de la vida social y una evolución asociada a una progresiva pérdida de prioridad de los objetivos sociales y ambientales en la gestión pública. A lo largo de esta trayectoria, en la que EE.UU. se situó como el foco innovador central, se concibieron y materializaron los arreglos institucionales que establecieron las condiciones para intensificar la articulación bajo una "lógica financiera general" de los componentes básicos de la organización capitalista, lo cual se constituyó en el referente obligado para los cambios que irían operarse en otras partes del mundo. De esta manera se logró la conformación de un "patrón sistémico" financiarizado, en cuyo contexto se consolidó una dinámica estructural que impuso el predominio de lo financiero sobre lo productivo en diversas entidades nacionales (Braga, 1997).

En otras palabras, lo que ocurrió fue que "el capitalismo ha padecido una completa mutación: la de la financiarización de la economía. La que no concierne solamente al sistema financiero; esta lógica penetra toda la economía, haciendo de la empresa un actor financiero dedicado a la valorización de los ingresos de los accionistas" (Aglietta, 2013, pag. 
57). Vale decir, con el avance del proceso de financiarización como configuración capitalista dominante, las decisiones de inversión y acumulación pasaron a estar regidas por los criterios de la gobernanza corporativa (corporate governance), cuya vigencia redundó en que la rentabilidad de las inversiones fuese colocada en forma compulsiva como objetivo ineludible de la gestión empresarial.

Fue así que en estos años se produjo la creación y aplicación de un vasto conjunto de instrumentos, mecanismos y/o procedimientos al servicio de la operación y consolidación de la lógica financiera, la cual de esta manera logró proyectarse hacia un ámbito geográfico cada día mayor. En esta dirección, es posible mencionar a las principales acciones impulsadas por diversos gobiernos nacionales, orientadas a insertar a los mismos en la dinámica financiarizada que día a día invadía nuevos lugares en diversas partes del planeta, entre las cuales se destacan:

1. consolidación y modernización del sistema bancario, a fin de otorgarle mayor capacidad para generar y operar los flujos de capital a escala planetaria y, en especial, para ampliar sus atribuciones en el manejo del crédito y en la generación de capital ficticio;

2. articulación y jerarquización de las bolsas de valores, de forma de generalizar e intensificar su incidencia en la regulación y encauzamiento de los movimientos de capital escala internacional;

3. generación de amplia variedad de nuevos productos financieros (swaps, derivados, etc.) y de mecanismos para el funcionamiento de los mercados financieros a escala global, donde la "securitización" (titulización) permitió la transformación de activos reales e inmóviles (inmuebles, infraestructuras) en activos financieros (líquidos y móviles) negociables en los mercados financieros;

4. introducción de nuevos tipos de inversores institucionales (fondos de pensiones, fondos de inversión, compañías de seguros, fondos mutuos, 
etc.), capaces de operar diversos mecanismos de capitalización individual y de manejar la cosecha y siembra de capitales a escala nacional y global;

5. establecimiento y multiplicación de diversos tipos de paraísos fiscales, aptos para cumplir con actividades relacionadas con la recolección y la colocación de capitales, incluyendo los procedentes del crimen organizado, que han cobrado creciente importancia; $y$

6. generación de un sistema bancario en la sombra (shadow banking system), compuesto por un conjunto de entidades financieras (incluyendo "hedge funds", fondos de mercados de capitales, vehículos de inversión estructurados, etc.), que promueven operaciones financieras que se realizan fuera del alcance de las entidades nacionales e internacionales de regulación.

Sustentada por esta compleja, diversificada y cambiante arquitectura institucional, el propio avance de la lógica financiera generó las condiciones apropiadas para su posterior despliegue por todo el laberinto de la vida económica y social a escala nacional y mundial. De esta manera, en el ámbito geográfico que así se configuró, los flujos financieros pasaron a regirse por los criterios de la "corporate governance" y a ser operados conforme a las reglas del juego establecidas por los arreglos institucionales prescriptos por el "ajuste estructural". Por lo que desde entonces las principales dinámicas del circuito global pasaron a moverse principalmente en la esfera financiera. En este sentido, como destaca Chesnais (2003), "a partir de mediados de los 80 el capital financiero ha adquirido una trascendencia que le permite influir significativamente en el nivel y la orientación de las inversiones, así como en la estructura y la distribución de la renta" (pag. 38). Con ello, se produjo un vertiginoso aumento de la importancia del capital ficticio, generado en base al crédito bancario, a los títulos de deuda pública y a las acciones, como un mecanismo especulativo orientado a la captura anticipada de valor futuro (Lohoff y Trenkle, 2014). 
La modalidad de funcionamiento emergente, que así tendió a imponerse a todos los niveles, desde el de las grandes operaciones macroeconómicas que marcan la expansión de la dinámica económica mundial a su nivel superior, hasta el de la vida cotidiana de cada una de las comunidades afectadas, en sus diversas escalas (local, regional, urbana, nacional, etc.), contribuyó a imponer en forma generalizada los comportamientos que impulsan la dinámica económica de una sociedad de consumo. Desde esta óptica, se justifica la afirmación de que "la economía financiera es hoy invasiva, se expande a lo largo de todo el ciclo económico. Lo acompaña, por así decir, desde el inicio hasta el final. [...]" (Marazzi, 2009, 30)

De hecho, este carácter invasivo logró la adscripción a la lógica financiera, aún sea en forma parcial, de naciones ubicadas en diversas partes de un ámbito geográfico que, de esta manera, tendió a constituirse en un espacio planetario de valorización del capital. Ante el avance de este proceso, $-\mathrm{y}$ dado el fracaso de los intentos realizados por diversos gobiernos por encontrar caminos alternativos que permitiesen reactivar al modelo keynesiano-fordista-, muchas de esas naciones terminaron por optar, total o parcialmente, por este derrotero. Lo cual las llevó a realizar las reformas y establecer los arreglos institucionales preconizados por la receta neoliberal, de forma de lograr su articulación al espacio financiarizado de acumulación.

Del avance de este proceso da cuenta, entre otros, un estudio del World Economic Forum (2012) en el que se consignan los resultados de una evaluación sobre el el nivel de financiarización en el mundo, en el que se incluyen 62 países, entre los cuales 8 latinoamericanos. Esta situación aparece como resultado de un proceso que ha caracterizado por diversas marchas y contramarchas y por contradicciones inherentes a esta fase del desarrollo capitalista, pero que sin embargo hasta ahora ha continuado su marcha sin que se le hayan interpuesto caminos alternativos 
capaces de suscitar consenso político a nivel internacional. Por ello, como señalan Lohoff y Trenkle, "desde entonces, la transformación radical del mundo en un espacio de valorización transnacional no rencontró prácticamente más límites" (2014, pag. 69).

Bajo esta dinámica invasiva, un número cada día mayor de actividades que forman parte de la vida cotidiana en diversos lugares del mundo, _-muchas de las cuales en el pasado habían operado fuera del ámbito mercantil_, terminaron por ser sometidas a las exigencias de la lógica financiera. Frente a ello, puede concluirse que con la vigencia de un régimen de acumulación financiarizado, al ampliarse y consolidarse el espacio mundial de acumulación, se generó un nuevo encuadramiento estructural, en el cual prevalece una situación regida por los criterios básicos de la lógica mercantil y financiera.

\section{Sobre-acumulación y valorización inmobiliaria del capital}

Con la generalización de la dinámica económica financiarizada, el proceso de producción social del espacio urbano comenzó mostrar cambios sustantivos tanto en lo que concierne a las relaciones interurbanas, como a la evolución de cada una de las áreas urbanas involucradas. En lo fundamental, puede considerarse que estos cambios están relacionados con el sustantivo aumento que se produjo con la financiarización en la capacidad de la urbanización para absorber los excedentes de capital. El hecho es que, como ha señalado Harvey (2013), "la urbanización [...] ha desempeñado un papel crucial en la absorción del excedente de capital, y lo ha hecho a una escala geográfica cada vez mayor [...]" (pag. 5). El cambio específico que concierne a esta fase del desarrollo capitalista, es que bajo las condiciones establecidas por la configuración financiarizada, ese excedente de capital alcanzó una magnitud inconmensurablemente superior a la lograda en cualquier fase anterior del desarrollo capitalista. 
Esto ocurrió, desde el momento en que al profundizarse la crisis del fordismo se produjo una incontrolable acentuación de la caída de la rentabilidad del capital y, con ello, una acentuada ralentización del ritmo de inversión productiva en la economía real, lo cual, a su vez, redundó en una creciente sobre-acumulación de capital (Chesnais, 2001; Lohoff \& Trenkle, 2014). A partir de ese momento, el desafío que debió enfrentar la gestión del capital, fue encontrar una salida a dicha sobre-acumulación, la cual se configuró como un problema crítico, que se intentó enfrentar mediante la elección de nuevos destinos para la valorización o empleo del capital, entre los cuales los negocios inmobiliarios se situaron como una de las alternativas preferidas.

Fue así que, en una situación en la que prevaleció la continuidad de la urbanización, un sostenido aumento de los ingresos medios de las familias y un incremento de la demanda por nueva infraestructura inmobiliaria para las actividades productivas globalizadas, las áreas urbanas mejoraron su capacidad para absorber una parte significativa de los capitales sobre-acumulados. De hecho, se trata de un fenómeno que ya había sido previsto y caracterizado por Lefebvre (1970), quien al diagnosticar y explicar la revolución urbana, planteó que con la inevitable caída de la rentabilidad de las inversiones en el sector industrial, se incrementaría el monto de capitales que se desviaría hacia un "segundo circuito" de acumulación: "mientras que baja el grado de plus-valía global formada y realizada por la industria, crece el grado de plusvalía formada y realizada en la especulación y mediante la construcción inmobiliaria. El segundo circuito suplanta al principal. De accidental pasa a ser esencial" (Lefebvre, 1970, pag. 165). Y, al mismo, tiempo, esto trae aparejado que, "'el inmobiliario' y la construcción dejan de ser circuitos secundarios y ramas anexas al capitalismo industrial y financiero, para pasar al primer plano" (Lefebvre, 1972a, pag. 120). 
Con el estallido de la crisis del régimen fordista, y bajo los efectos de la imposición de la lógica financiera, esta anticipación de Lefebvre adquirió plena validez, desde que al intensificarse la sobre-acumulación de capital, la mayoría de las fuerzas económicas que en esta fase lideraron la dinámica económica mundial intensificaron sus esfuerzos por encontrar un destino que permitiese valorizar o emplear este excedente de capital. De hecho, lo que ocurrió es que la mayor parte de los capitales sobre-acumulados se orientaron principalmente hacia actividades especulativas en el "segundo circuito", sin con ello solucionar el problema de la sobre-acumulación en su conjunto. En tales circunstancias, como señalan Lohoff y Trenkle (2014), la búsqueda de alternativas para su empleo continuó presentándose como un desafío sin respuesta:

A nivel global, la sobreacumulación estructural de capital no se mitigó de manera alguna, y ella adquirió bien por lo contrario proporciones incesantemente más inquietantes. Cantidades siempre más importantes de capitales se reencontraron de alguna manera "sin empleo" y comenzaron a vagabundear a través del globo a la búsqueda de ocasiones de colocaciones rentables (pag. 69),

Por lo tanto, esos capitales "sin empleo" continuaron su "vagabundeo" a escala planetaria, en una infatigable exploración en busca de destinos geográficos y sectoriales que pudiesen ofrecer mejores condiciones para su valorización. Y, en ese proceso exploratorio, los potenciales inversores comprobaron que en una configuración global financiarizada, en la que la urbanización económica y poblacional proseguía su avance, eran las áreas urbanas mejor articuladas al espacio financiarizado de acumulación, las que podían ofrecer mejores condiciones para la valorización de sus capitales. De tal modo, fueron esas áreas, las que se constituyeron en la infraestructura geográfica básica en la que encontró destino una parte creciente del excedente de capital. Así, en forma compatible con 
la ampliación de la economía-mundo, un número importante de áreas urbanas de distintas partes del mundo, —entre las cuales diversas latinoamericanas-, se fue adscribiendo a dicho espacio financiarizado de acumulación, si bien con funciones e intensidad variables. A lo largo de este proceso, la base económica de dichas áreas sufrió modificaciones que afectaron a su estructura productiva, la cual fue objeto de una progresiva terciarización, donde el "segundo circuito" registró un fuerte crecimiento.

Por otra parte, ese proceso de crecimiento del "segundo circuito" se benefició de los arreglos institucionales relativos a la titulización (securitización) de activos inmobiliarios, que permitieron que las operaciones respectivas pudiesen desarrollarse en un circuito titulizado e intermediado, en remplazo del circuito no titulizado y directo dominante en la fase anterior; de esta forma, los inversores institucionales (sociedades y fondos de inversión inmobiliaria, compañías de seguro, fondos mutuos, etc.), en su mayoría vinculados a grupos bancarios, pasaron a actuar como los principales intermediadores. En lo fundamental, dichos arreglos institucionales hicieron posible transformar activos reales e inmóviles (inmuebles, infraestructuras), en activos financieros negociables en los mercados financieros. De esta forma, los inversores institucionales e, incluso los particulares, pudieron invertir en forma indirecta en los mercados reales de la construcción urbana, principalmente por vía de portafolios de inversión. Y, con ello, también fue posible que la propiedad urbana inmóvil pasase a ser líquida y móvil en el espacio, lo que favoreció un sustantivo incremento del monto de capital financiero destinado a negocios inmobiliarios en las áreas urbanas respectivas.

En ese contexto, el sector inmobiliario y la industria de la construcción adquirieron una magnitud mucho mayor que en el pasado, haciendo que sus inversiones y negocios tuviesen una influencia cada día mayor en la mercantilización de la respectiva metamorfosis urbana. Además, en ello 
tuvo una importante incidencia el hecho de que con la afirmación y profundización de la financiarización, el conflicto entre valor de uso y valor de cambio se dirimiese a favor de aquel, que así pudo consolidar su supremacía sobre el primero. En definitiva, todo ello permite concluir que la consolidación de la lógica financiera incidió decisivamente en la creciente mercantilización de los procesos de producción de espacio urbano.

Lo cual, avala la conclusión de que bajo el impacto de la financiarización se produjo la consolidación de una situación en la que "la ciudad (lo que queda de ella o en lo que se convierte) es más que nunca un instrumento útil para la formación de capital, es decir, para la formación, la realización y la repartición de la plusvalía" (Lefebvre, 1970, pag. 42). El proceso que llevó a la consolidación de esta situación, que se originó asociada a la revolución industrial, alcanzó su culminación con la adopción de las reformas y políticas del "ajuste estructural" y la consecuente imposición generalizada de la lógica financiera.

Impactos inter e intra-urbanos de la financiarización

Desde que los procesos de financiarización se fueron desplegando hacia una economía-mundo que continuó ampliándose de período en período, la metamorfosis urbana que entonces se intensificó, derivó en mutaciones que afectaron tanto a las relaciones entre ciudades, como a cada área urbana en sí misma, en la forma siguiente:

a) en el plano inter-urbano, el cambio fundamental radica en que al multiplicarse e intensificarse las articulaciones y flujos (productiv0s, financieros, comerciales y de consumo, comunicacionales, etc.), en procesos en los que las TIC tuvieron una incidencia fundamental, llevaron a la conformación de una red urbana global (RUG) —o "word city network" en la terminología de Taylor (2004)_, en la que las distintas áreas 
urbanas intensificaron su inter-relación a escala global, conforme a los requerimientos de la lógica financiera;

b) y, en lo que concierne a la dimensión intra-urbana, lo fundamental radica en que bajo el impacto de la financiarización, a medida que cada área urbana se fue ensamblando a la RUG, al interior de cada una de ellas comenzaron a producirse mutaciones, que si bien se configuraron en forma desigual, en términos generales respondieron a la tendencia a la implosión/explosión que se manifestó con alcance planetario (Lefebvre, 1970; Brenner, 2013). Esta tendencia marcó la metamorfosis de la "ciudad" en lo urbano generalizado, en una dinámica de urbanización planetaria.

Específicamente, en lo que atañe a la dimensión inter-regional, los flujos financieros que se orientaron hacia inversiones y negocios en el "segundo circuito" mostraron una marcada preferencia por aquellos componentes de la RUG que fueron percibidos como los lugares que ofrecían mejores condiciones para la valorización y/o empleo del capital. Esto es, la estructura económico-geográfica que se había formado con la división internacional del trabajo imperante a lo largo de las primeras fases del capitalismo industrial, marcada por fuertes desigualdades de desarrollo entre los diferentes países, ciudades y regiones que la componían, se constituyó en la base de operaciones de las inversiones financiarizadas.

Al haber sido esta la estructura económico-geográfica sobre la que se desplegó la dinámica económica globalizada y financiarizada, los propietarios del capital consideraron las diferencias inter urbanas de desarrollo pre-existentes, para decidir el destino de sus inversiones.

Fue así que los capitales "sin empleo" mostraron una fuerte preferencia por las áreas urbanas evaluadas como más atractivas para su valorización, las cuales en su gran mayoría estaban situadas en los países de mayor desarrollo relativo. En consecuencia, esta preferencia, operó principalmente en beneficio de las áreas urbanas que en el pasado ya habían 
logrado un mayor desarrollo relativo, razón por la que este mecanismo incidió en la retroalimentación de las desigualdades pre-existentes.

¿Cuál fueron los principales efectos de estas tendencias sobre la formación de la actual estructuración inter-urbana y del nuevo "espacio global de valorización del capital"? Como ya hemos mencionado, al imponerse una dinámica relacional sustentada en las nuevas condiciones de conectividad y movilidad, las áreas urbanas que comenzaron a cumplir las funciones básicas en la nueva configuración tendieron a irse articulando en una red urbana cada día más fuertemente inter-conectada. Bajo esta dinámica, cada área urbana articulada a la RUG pasó a constituirse en un nodo de coordinación, control y servicios del capital financiero que se despliega a escala global (Sassen, 1994). Y, para cumplir con este papel, en cada una de esas áreas urbanas se intensificó la utilización de estrategias de competitividad a fin de atraer inversiones financieras y productivas, en el entendido de que la competitividad constituía un requisito ineludible para promover el crecimiento económico.

Además, estos procesos se desarrollaron impulsados por una gestión pública que, conforme a las recetas del ajuste estructural, se basó en la utilización de estrategias de "partenariado" público-privado, cuya aplicación, en aras de preservar el equilibrio fiscal, llevó a que la mayor parte de las actividades urbanas pasaran al sector privado. A este respecto, se debe tener presente que bajo la influencia de un discurso teórico-ideológico que privilegia el papel subsidiario del Estado, la austeridad fiscal y el partenariado público-privado, la gobernanza neoliberal se manifestó en un nuevo enfoque de gestión urbana:

como respaldo del empresarialismo urbano, se consolida un proceso que puede ser considerado como una tercerización de la planificación y de la gestión de la ciudad, o [...] de transferencia de las atribuciones de control del uso y de ocupación del suelo y de la formulación de políticas, planes 
y proyectos de desarrollo urbano desde la esfera pública hacia la esfera privada (Carvalho y Pereira, 2013, p. 20)

De esta forma, las áreas urbanas que pudieron aumentar su atractividad y mejorar su inserción en la RUG, se beneficiaron con la localización de variados servicios, - entre los cuales los servicios financieros se constituyeron en el núcleo de la nueva base económica-, cuyos efectos intra-urbanos implicaron la paulatina modificación de su respectiva base económica y, en consecuencia, del correspondiente mercado de trabajo.

¿Cuáles se pueden considerar como los principales efectos, tanto en términos inter como intra urbanos, del proceso de financiarización sobre la actual metamorfosis urbana? En una aproximación de carácter general, importa destacar los impactos sobre los siguientes aspectos o dimensiones:

\section{Sobre la magnitud de los flujos financieros destinados a inversiones} inmobiliarias: en virtud del efecto de los arreglos institucionales implementados como parte del "ajuste estructural", que contemplaron entre otros el establecimiento de múltiples instituciones y mecanismos financieros que viabilizaron la libre circulación de capitales a escala global y generaron condiciones para que un volumen creciente de los capitales "sin empleo" se canalizase hacia inversiones en el segundo circuito, las realizadas en bienes raíces adquirieron una magnitud incomparablemente superior a la que habían alcanzado en fases anteriores. En consecuencia, el crecimiento de las inversiones inmobiliarias tuvo, y continúa teniendo, una mucho mayor incidencia que en el pasado en las transformaciones urbanas, las cuales han modificado en forma sustantiva la organización, el funcionamiento, la morfología y la apariencia de las principales aglomeraciones urbanas del mundo.

\section{Sobre el destino inter-urbano de las inversiones inmobiliarias: con} la creciente socialización de la gestión de los negocios inmobiliarios (de inversores individuales a inversores institucionales) los flujos de capi- 
tal han tendido a dirigirse preferentemente hacia los componentes de la RUG percibidos y/o evaluados como los lugares que ofrecen mejores condiciones para su valorización. Con el avance de estos procesos, comenzaron a realizarse regularmente diferentes tipos de evaluación sobre la competitividad de las diferentes áreas urbanas del mundo, en las que invariablemente resultaron mejor calificadas las principales "ciudades" ubicadas en los países más desarrollados y/o financiarizados del mundo. Lo cual está fuertemente correlacionado con el hecho de que los inversores han tendido a priorizar a estas "ciudades" al adoptar sus decisiones de inversión, con lo cual han contribuido a retroalimentar una geografía heredada de fases anteriores marcada por fuertes desigualdades inter-urbanas.

\section{Sobre la implosión/explosión de las áreas urbanas en crecimiento:}

En un escenario mucho más receptivo para los negocios inmobiliarios, el incremento de las inversiones en el segundo circuito de acumulación, contribuyó en forma importante a la ocurrencia del fenómeno que Lefebvre caracterizó como "implosión/explosión": "[... l la enorme concentración (de gente, de actividades, de riqueza, de cosas y objetos, de instrumentos, de medios y de pensamiento) en la realidad urbana, y el inmenso estallido, la proyección de múltiples y dispersos fragmentos (periferias, arrabales, residencias secundarias, satélites, etc." (Lefebvre, 1970, pag. 24). Estos procesos, en los que también influyó la persistencia de la urbanización de la economía y de la población, impusieron la necesidad de producir espacio adicional, lo que ha producido procesos hasta ahora prácticamente incontrolables de expansión territorial del tejido urbano hacia los arrabales, que por lo general se han traducido en un fuerte aumento del consumo de tierra per cápita y en la formación de áreas urbanas en las que los límites entre lo urbano y lo rural tienden a ser cada día más difusos. 


\section{Sobre la desigual distribución intra-urbana de las inversiones inmo-}

biliarias: la evidencia empírica muestra que ha sido en las partes de cada espacio urbano en que residían los sectores de mayores ingresos y el precio de la tierra era más elevado, donde los promotores e inversores inmobiliarios percibieron la existencia de una mayor demanda solvente, tanto para vivienda como para servicios. Y, por tanto, fue hacia ellas hacia las que se dirigió el mayor volumen de las inversiones inmobiliarias. Por lo contrario, las áreas de residencia de los sectores más pobres y con más baja demanda solvente, terminaron recibiendo inversiones inmobiliarias de mucho menor entidad, tanto para destino residencial como empresarial. De esta manera, en la medida que los promotores y/o inversores inmobiliarios, bajo las exigencias impuestas por la lógica financiera, priorizaron las partes de cada área urbana que presentaban mayores ventajas para la valorización de sus inversiones, con ello contribuyeron a la permanencia de las desigualdades socio-territoriales heredadas de fases anteriores.

\section{Sobre el aumento de la demanda habitacional y del crédito hipote-} cario: el crecimiento de la población urbana y del ingreso medio de las familias, impulsó una reactivación de la demanda inmobiliaria residencial que tuvo como respuesta un aumento de capitales "sin empleo" interesados en los negocios inmobiliarios de carácter residencial. Frente a ello, con el avance de los procesos de financiarización se impuso la modernización de los respectivos sistemas de crédito hipotecario bajo modalidades nacionales diversas, lo cual permitió aumentar en forma significativa el acceso al mismo de un número creciente de familias en el mundo entero. Estos sistemas, asociados por lo general a formas específicas de titulización, permitieron multiplicar los negocios e inversiones inmobiliarias en vivienda, que pasaron a constituirse en uno de los principales motores del segundo circuito de acumulación. Por otra par- 
te, al constituirse en mecanismos idóneos para la generación de volúmenes crecientes de capital ficticio, estos sistemas permitieron generar financiamiento adicional para un sostenido aumento de la inversión en vivienda en los momentos ascendentes del ciclo económico. Y también para la formación de burbujas inmobiliarias, cuyo estallido ha tenido nefastos impactos en las respectivas economías nacionales y en el resto del mundo hacia el que se propagaron.

\section{Sobre el aumento de las operaciones de "destrucción-creativa" y de} "gentrificación": a medida en que se fue reduciendo la disponibilidad de suelo edificable en las partes más consolidadas (y rentables) de cada espacio urbano, los inversores inmobiliarios intensificaron sus operaciones de "destrucción creativa", por las que remplazaron partes del medio ambiente construido de baja densidad por nuevas edificaciones capaces de albergar un mayor número de familias. Con ello, al mismo tiempo que lograron generar nuevos negocios inmobiliarios, también incidieron en una persistente re-densificación y verticalización de partes importantes de los respectivos espacios urbanos. De tal forma, por la vía de la verticalización y la re-densificación de esas áreas, se logró impulsar un nuevo tipo de negocio inmobiliario, que desde entonces ha venido teniendo un impacto significativo en la transformación y mercantilización del desarrollo urbano. Por otra parte, también en función de la escasez de suelo urbano en las zonas más rentables de cada área urbana, se han impulsado operaciones de reconversión y revalorización de ciertas partes centrales de las áreas urbanas consolidadas, lo cual por lo general ha estado asociado a la expulsión de sectores de menores ingresos para ser remplazados por nuevos sectores burgueses (gentries). Al permitir una importante absorción de los excedentes de capital, estas operaciones originaron un tipo de negocio inmobiliario, que ha tendido a multiplicarse en las grandes áreas urbanas en expansión, pasando a 
constituirse en otra alternativa atractiva para el empleo y valorización de los excedentes de capital.

7. Sobre la proliferación de nuevos productos inmobiliarios: bajo el impacto de la globalización financiera y de las innovaciones que han afectado la vida cotidiana en la sociedad emergente, un amplio conjunto de nuevos productos inmobiliarios se constituyó en un destino atractivo para la absorción de los capitales "sin empleo". Al respecto, en particular, cabe mencionar a diversos nuevos artefactos para el consumo (v. gr.: malls, strip-centers, super e hipermercados, tiendas de conveniencia, grandes tiendas de comercio minorista, etc.), cuya presencia justifica la afirmación de que hemos evolucionado desde la ciudad como "máquina de producción" hacia la ciudad como "máquina de consumo" (Soja, 1990). Además, la creciente incidencia de los servicios a las empresas y a las familias, generó una amplia y diversificada demanda por nuevos productos, así como también lo ha hecho el turismo, en especial en rubros como hotelería y gastronomía. Por otra parte, entre esos nuevos productos inmobiliarios, cuya presencia modifica partes emblemáticas del paisaje urbano, se destaca cierta infraestructura inmobiliaria para el esparcimiento y la cultura y, en especial, los edificios de gran altura, que tienden a ser utilizados como emblemas de paisaje urbano globalizado y como "marca" que permite individualizar a cada ciudad en la competencia inter-urbana. Todo ello generó múltiples nuevas oportunidades para la utilización de los excedentes de capital, lo que ha estimulado el sobredimensionamiento del segundo circuito de acumulación en muchas partes del mundo. 


\section{Conclusiones}

Los efectos reseñados hasta aquí, pueden considerarse como los de mayor influencia en el establecimiento de la dirección y el contenido de la actual metamorfosis urbana y, por consiguiente, en la conformación de la nueva geografía de la urbanización. En cualquier caso, hay que tener presente que estos efectos se han presentado en su expresión más avanzada en las áreas urbanas ubicadas en los países con mayores niveles de financiarización y que, por esta razón, se evalúan como los más competitivos y con mayor capacidad para la absorción de excedentes de capital. Frente a este panorama, dos consecuencias generales merecen ser destacadas.

Por una parte, una primera consecuencia se relaciona con el hecho de el éxito de buena parte de las experiencias de renovación urbana impulsadas con la finalidad de aumentar la competitividad frente a los capitales móviles, Ilevaron a que se produjese un aumento de la dependencia de las áreas urbanas respectivas con respecto al capital financiero que en ellas se valoriza. Es así que se puede mencionar como un ejemplo paradigmático de esto, el de Barcelona, considerado como uno de los casos más exitosos de gestión empresarialista. Ha sido justamente debido a su éxito, que esta ciudad ha permanecido en la mira de los inversores externos, por lo que, como ha señalado Manuel Delgado, "quien ansía ocupar Barcelona y avasallarla es, hoy, un capitalismo financiero internacional que ha descubierto en el territorio una fuente de enriquecimiento y que aspira a convertir la capital catalana en un artículo de consumo con una sociedad humana dentro" (Delgado, 2007, p. 11).

Esta conclusión acerca del riesgo que corren ciertas áreas urbanas de convertirse en "un artículo de consumo con una sociedad humana dentro", tiene complejas y preocupantes consecuencias para su evolución futura. Una de esas consecuencias es que, con el propósito de aumentar 
su atractividad frente a los capitales en movimiento, en muchas de ellas se han desarrollado proyectos que implican una verdadera museificación (o "disneylandización") de sus espacios históricos, para lo que se han realizado cambios sustantivos difíciles de revertir. Todo esto ocurre, en el contexto de una tendencia por la que la museificación de áreas históricas de cada espacio urbano, se realiza tratando de atender ante todo los intereses y las apetencias de los turistas, en desmedro de los de sus residentes habituales, cuya vida cotidiana tiende a ser alterada en forma radical.

Por otra parte, como consecuencia de los procesos de implosión-explosión, las ciudades involucradas comenzaron a padecer una metamorfosis de la que ha surgido una incontenible urbanización del espacio externo, por lo que los límites entre lo urbano y lo rural han resultado ser cada día más difíciles de establecer. El análisis de estos procesos por los que lo urbano se despliega hacia un espacio de límites difusos y móviles, ha llevado a Brenner y Schmid (2013), a argumentar que frente a las propuestas de la mayoría de las corrientes tradicionales, en las que lo urbano es tratado como un tipo particular de espacio limitado de asentamiento (la "ciudad"), se contrapone la idea de que lo urbano, "y el concepto de urbanización que le está estrechamente asociado" debe ser entendido como una abstracción teórica. Por ello, proponen considerar a lo urbano como una categoría teórica, no como un objeto empírico, de igual forma a como era considerado lo rural en el pasado.

En esa situación, nos enfrentamos a enormes desafíos, frente a los cuales hasta ahora no ha habido decisiones y acciones políticas efectivas. Mientras tanto, se han continuado agravando los principales problemas que afectan a estas áreas urbanas, donde se destaca el aumento de las desigualdades sociales, la extrema concentración de la riqueza y la progresiva, y hasta ahora incontrolable, destrucción de la biósfera. En particular, el proceso de destrucción de la biósfera, merecería una atención 
prioritaria dado que su avance está amenazando con poner fin al proceso de producción social de espacio y, con ello, está poniendo en cuestión la propia supervivencia del capitalismo.

En cualquier caso, lo que resulta más inquietante, es que existen múltiples razones que avalan la convicción de que la generación y/o profundización de estos problemas está indisolublemente asociada a la profundización de la configuración financiera. Lo cual estaría validando, como conclusión final, que mientras continúen siendo aplicados los criterios y recetas del "neoliberalismo realmente existente" en sus diversas modalidades, no parece posible prever cambios significativos en el contenido y la dirección de la actual metamorfosis urbana, con todas las consecuencias que esto implica.

Carlos A. de Mattos: Profesor Titular Adjunto del Instituto de Estudios Urbanos y Territoriales de la Pontificia Universidad Católica (PUC) de Chile. Teléfono: 5602 23545518.\cdmattos@uc.cl

\section{Referencias}

1. AGLIETTA, M. Le marché du travail n'est pas le problème (Entretien), Alternatives Economiques, Paris, Hors Serie, n. 099, diciembre 2013, p. 56-58

2. BRAGA, J. C. S. Financeirização global. O padrão sistémico de riqueza do capitalismo contemporáneo. En TAVARES, M. C. \& J. L. FIORI, Poder e dinheiro. Uma economia política da globalização. Petrópolis, Brasil, Editora Vozes, 1997, pp.195-242.

3. BRAUDEL, F. La dinámica del capitalismo, Madrid, Alianza Editorial. 1985.

4. BRENNER, N. Tesis sobre la urbanización planetaria. Nueva Sociedad, n. 243, enero-febrero 2013, p. 38-65.

5. BRENNER, N.; SCHMID, C. Towards a new epistemology of the urban? City, v. 19, n. 2-3, 2013, p. 151-182.

6. CARVALHO, I. M. de; PEREIRA, G. A cidade como negócio. EURE, Santiago, v. 39, n. 118, setiembre2013, pp. 5-26. 
7. CHESNAIS, F. La teoría del régimen de acumulación financiarizado: contenido, alcance, interrogantes. Revista de Economía Crítica, n. 1, abril 2003, pp. 37-72. 8. CHESNAIS, F. Crise de suraccumulation mondiale ouvrant une crise de civilisation. http://www.preavis.org/breche-numerique/article1928.html 2010

9. DELGADO, M. La ciudad mentirosa. Fraude y miseria del modelo Barcelona. Madrid, Los Libros de la Catarata, 2007

10. HARVEY, D. Ciudades rebeldes. Del derecho a la ciudad a la revolución urbana. Madrid, Ediciones Akal, 2013.

11. LEFEBVRE, H. Le droit à la ville. Paris, Anthropos, 1968.

12. LEFEBVRE, H. La révolution urbaine. Paris, Éditions Gallimard, 1970.

13. LEFEBVRE, H. Espace et politique. Le droit a la ville II. Paris, Éditions Anthropos. $1972 \mathrm{a}$

14. LEFEBVRE, H. La pensée marxiste et la ville. Paris, Casterman, 1972b.

15. LEFEBVRE, H. La production de I'espace. Paris, Anthropos, 4aㅡ Edición, [1974] 2000.

16. LEFEBVRE, H. Quand la ville se perd dans la métamorphose planétaire. Paris, Le Monde Diplomatique, mai 1989.

17. LOHOFF, E.; TRENKLE, N. La grande dévalorisation. Ile de France, PostEditions, 2014.

18. MARAZZI, C. La violencia del capitalismo financiero. En FUMAGALLI, Andrea et al. La gran crisis de la economía mundial. Madrid, Traficantes de Sueños, 2009.

19. MICHALET, C.-A. Mondialisation, la grande rupture. Paris, La Decouverte, 2007.

20. MICHALET, C.-A. Qu'est-ce que la mondialisation? Petit traité à I'usage de ceux et celles qui ne savent pas s'il faut être pour ou contre. Paris, La Decouverte, 2004.

21. SASSEN, S. Cities in a World Economy. Londres, Pine Forge Press/Sage Publications, 1994.

22. SOJA, E. W. Posmodern Geographies. The Reassertion of Space Social Theory. Londres, Verso/New Left Books, 1990.

23. TAYLOR, P. J. World City Network. A Global Urban Analysis. New York, Routledge, 2004. 
24. WALLERSTEIN, I. The Rise and Future Demise of the World Capitalist System: Concepts for Comparative Analysis. Comparative Studies in Society and History, v. 16, n. 4. sept. 1975, pp. 387-415.

25. WORLD ECONOMIC FORUM. The Financial Development Report 2012 http://www.weforum.org/reports/financial-development-report-2012

Recebido: 12.02.2016

Aceite final: 16.04.2016 